\title{
Parentesco silenciado. Luis XIV y los Austrias mayores
}

\author{
Sylvène ÉDOUARD \\ Maître de conférence HDR, Université Lyon 3 - LARHRA \\ sylvene.edouard@gmail.com
}

Recibido: 31 de marzo de 2011

Aceptado: 3 de febrero de 2013

\begin{abstract}
RESUMEN
El objetivo de este artículo es mostrar el puesto que los Austrias mayores ocuparon en la educación y en el discurso de grandeza de Luis XIV, descendiente directo por parte de madre, Ana de Austria, y ligado a la familia habsbúrgica de Viena por su abuela María de Médicis, nieta del emperador Fernando I. En un tiempo de cambio hegemónico, los turiferarios del rey de Francia, la mayoría académicos, tuvieron constatable dificultad en nombrar este parentesco para gloria de su amo. Carlos V y Felipe II habían sido las figuras dominantes del precedente siglo sin que su prestigio redoblara el de su descendiente. Pero si no se presentó a Luis XIV como heredero suyo, al menos se le educó en el conocimiento de aquellos dos ancestros ejemplares, para terminar captando la esencia del imaginario imperial de los Austrias.
\end{abstract}

Palabras clave: Luis XIV, educación, genealogía, Carlos V, Felipe II.

\section{No mention kinship. Louis XIV and the Great Habsbourg}

\begin{abstract}
The aim of this paper is to show the place of Austrias mayores in Louis XIV's education and discourse of greatness, who was their direct descendant by his mother Ana of Austria, and linked with those of Vienna by his grandmother Marie de Medici, grand-daughter of Emperor Ferdinand Ist. In this time of hegemony's changeover, the apologists of the King of France, mostly academicians, experienced difficulties in naming this relationship to serve the glory of their master : Charles V and Philip II had been the dominant figures of the last century without their glory reflected upon their descendant. If Louis XIV was not presented as their heir, at least he has been raised in the knowledge of their exemplaries figures to eventually capture their Imperial's imaginery.
\end{abstract}

Key words: Louis XIV, education, ancestry, Charles V, Philip II.

"La sangre de Carlos V le daba altura"... Una filiación límpidamente expresada. Sin embargo, concluyendo con estas palabras, Madama de Motteville no pensaba en el joven Luis XIV sino en Ana de Austria ${ }^{1}$. Lo que constituía la grandeza de la madre

1 Madama de Motteville, Chroniques de la Fronde, París, Mercure de France, 2003, p. 77. 
no había de contribuir necesariamente a la del rey de Francia, dejando así vislumbrar una relación bastante tenue con los parientes Habsburgo. En materia de lazos de parentesco, la herencia reivindicada por Luis XIV fue ambivalente, lo que quizás haya inducido a Gérard Sabatier, historiador del "Gran Siglo", a enunciar un "complejo de Carlos V" para significar a la vez la tentación de asemejarse al heroico conquistador de Túnez y la voluntad de revancha sobre la España preponderante ${ }^{2}$. Historiógrafos, panegiristas, astrólogos y otros cultivadores de la grandeza del rey, a menudo en el seno de la Academia francesa, sudaron tinta erudita para denominar a los parientes de "Luis el Grande". ¿Cómo estos últimos -La Mothe Le Vayer, Scudéry, Mézeray, Carel, Varillas, Péréfixe y Bretaigne, entre tantos otros- consiguieron conciliar parentesco y rivalidad con los Habsburgo de España en aquel tiempo de cambio hegemónico? En la perspectiva de los imaginarios vinculados a los discursos imperiales establecidos bajo las monarquías española y francesa, conviene preguntarse el lugar que ocuparon realmente los Austrias mayores en la edificación del discurso de grandeza de Luis XIV, durante los años que median entre su educación teórica y el apogeo de su gloria en torno a 1680 .

\section{Galería de antepasados}

El dicurso hegemónico de los Austrias, a partir sobre todo del emperador Maximiliano I, se apoyaba en una tradición dinástica alimentada por una mitografía de sus orígenes, de sus miembros ejemplares y de sus atributos, fundada ella misma en la relación eficaz entre continuidad y legitimidad. La filiación, efectiva o imaginaria, permitía legitimar la idea de elección de una Casa reinante, llamada -como los Austrias en su tiempo- a guiar a la Cristiandad. Para Luis XIV, esta misma tradición estaba en juego y su elaboración se hacía necesaria, con o sin la familia habsbúrgica.

\section{2. ¿Qué mito de los orígenes para los Borbones?}

La galería de ancestros, material o escrita, no era solamente un lugar de memoria, era también un discurso que proyectaba sobre el descendiente y heredero las cualidades de sus antepasados. Según las circunstancias, prefiguraba al rey o lo representaba. En 1549, los españoles de Amberes financiaron un arco de triunfo para el futuro Felipe II, haciéndole desfilar ante sus ascendientes de las dos Casas, española y austríaca, legando cada cual al príncipe sus singulares virtudes. La tarea de historiadores y genealogistas consistía en figurarlo en relación con esta herencia, informando así sobre el significado de su discurso político. Los linajistas Hieronymus Gebwiler, Pietro Mareno y Wolfgang Lacio, entregados a la defensa de los Austrias, integraron tipos mitológicos necesarios para fundamentar la legitimidad del Imperio hispánico. Eran figuras que remitían a los orígenes fundadores, como la de Túbal, o a los mitos de la

\footnotetext{
2 SABAtIER, G.: Versailles ou la figure du roi, París, Albin Michel, Bibliothèque Histoire, 1999, p. 405.
} 
translatio imperii con Jasón y los argonautas, o a Eneas y la leyenda troyana ${ }^{3}$. La mitografía del origen, subrayada hasta la fantasmagoría, prestó armas a los detractores y a sus críticas, que transfirieron el combate político armado de las dos Casas enemigas al campo de la historia y de la genealogía. François de La Mothe Le Vayer, en su Discours de l'histoire contra Prudencio de Sandoval -dedicado al cardenal Richelieu en 1638- hizo no poco escarnio de ella: “¿Como es posible que haya mentes capaces de digerir tales quimeras? [...] a todos nos complacen las fábulas [...], lo cual sirve para sacar con gusto moralejas de las de Esopo [...], mas no para fundar seriamente los derechos de una Corona, y apoyar en ellas, mediante una historia, los intereses de los Estados".

La Mothe Le Vayer, que no parecía creer en la virtud eficaz de estos cuentos, ignoraba que el futuro Luis XIV triunfaría por el "evemerismo", convirtiéndose en una leyenda viva gracias a las fábulas enseñadas por Desmarets de Saint-Sorlin. Sin embargo, en 1638, en el inmediato contexto de la guerra hispano-francesa, el autor se hacía eco de una hispanofobia inspirada, tratando de derribar las fundaciones del edificio austríaco ${ }^{5}$. Desde entonces, adiós mito troyano, puesto que Desmarets afirmaba que Dion Crisóstomo había demostrado, mil quinientos años antes, que no hubo guerra de Troya. Ahora bien, la epopeya troyana fue, por excelencia, el mito imperial de los Austrias, herederos del Toisón de Oro a través de su ancestro borgoñón, cuyo atributo, el collar de la Orden, lucían en sus retratos pintados, invitando a las figuras míticas del ciclo a formar parte de su representación mesiánica ${ }^{6}$.

Tiempo era, para La Mothe Le Vayer, de privar a los españoles de sus pretensiones y restablecer por fin la auténtica, mayúscula Historia, la única compatible con el "honor de Francia", pues, dice el autor al cardenal Richelieu en su dedicatoria:

3 TAnner, M.: The Last Descendant of Aeneas. The Hapsburgs and the Mythic Image of the Emperor, New Haven and London, Yale University Press, 1993; Édound, S.: L'Empire imaginaire de Philippe II. Pouvoir des images et discours du pouvoir sous les Habsbourg d'Espagne au XVIe siècle, París, Honoré Champion, 2005.

4 La Mothe Le Vayer, F. de: Discours de l'Histoire, où est examinée celle de Prudence Sandoval, chroniqueur du feu Roy d'Espagne Philippe troisieme et Evesque de Pampelune, qui a escrit la vie de l'empereur Charles Quint, París, Jean Camusat, 1638, pp. 52-53: "Est-il possible qu'il y ait des esprits qui se puissent repaistre de telles chimères? [...] nous sommes tous amateurs de fables [...] Mais cela est bon pour se plaire à tirer des moralitez de celles d'Esope [...], et non pas pour fonder serieusement les droicts d'une Couronne, et appuyer sur elles dans une histoire les interests des Estats. " François de La Mothe Le Vayer (1588-1672), originario de una familia de juristas, y académico desde 1639, fue elegido por Richelieu para instruir al Delfín, con título de preceptor, tras haber publicado en 1640 De l'Instruction de M. le Dauphin. A pesar de lo cual, Ana de Austria le confió esta tarea de 1652 a 1660. Sus obras alimentaron en gran medida la antipatía francesa hacia España, reflejada en el Discours de l'Histoire. Gouverneur, S.: Prudence et subversions libertines. La critique de la Raison d'État chez François de La Mothe Le Vayer, Gabriel Naudé et Samuel Sorbière, París, H. Champion, 2005; Salazar, P. J.: "Sur la bonne chère rhétorique. La Mothe Le Vayer politique", dans Guion, B. y otros (eds.): Poétique de la pensée. Études sur l'âge classique et le siècle philosophique, París, H. Champion, 2006.

5 Schaub, J.-F.: La France espagnole. Les racines hispaniques de l'absolutisme français, París, Le Seuil, 2002.

6 La galera real de don Juan de Austria, capitán de la flota de la Santa Liga en 1571, fue decorada con pinturas anunciadoras de su victoria, evocando la expedición de Jasón y de los argonautas. EDOUARD, S.: "Argo, la galera real de Don Juan de Austria en Lepanto", Reales Sitios, Revista del Patrimonio Nacional, año XLIV, 172 (2007), pp. 4-27. 
Vería con gusto [Vuestra Eminencia] que se refutaran las calumnias de la historia más opuesta a la gloria de nuestra nación que puede leerse. Estoy convencido de que Vuestra Eminencia no hallará despropósito, ni quizás inútil, el que demuestre a los Extranjeros enemigos de nuestro nombre, cómo la licencia que se otorgan para difamarnos en sus historias, no queda sin repuesta. ${ }^{7}$

La estrategia de La Mothe Le Vayer para derribar la legitimidad de los españoles estribaba en denunciar sus fantasías. El futuro preceptor del Delfín apelaba a la razón contra los dichos de Prudencio inspirados por:

una maravillosa impertinencia [...] de empezar con un genealogía de Carlos V tan ridícula, explicada de padres a hijos desde Adán hasta él. Aunque nadie dude de su primera tabla, desde nuestro padre común hasta los hijos de Noé [...]. Pero, pasar del texto sagrado a las fábulas de Troya, y coser las verdades del Génesis con las ensoñaciones de un Berosius supuesto por Annius de Viterbo, y las del abad Tritemo, que son los primitivos autores de tan bella genealogía, dudo de que no haya en ello alguna impiedad. ${ }^{8}$

El compilador italiano Gregorio Leti, complaciente con la casa de Austria, a pesar de su afán de veracidad, y pretendiendo rechazar toda visión apologética, escribirá más tarde en defensa del emperador, contra "los que hoy se toman tanta molestia buscando sus orígenes en la más remota Antigüedad, y que sus enemigos combaten ", laudando a Carlos V, quien respondió a sus linajistas - "empeñados en envolver a aquel gran Emperador en nubes de tal naturaleza"- "que no era tan débil como para dar en tan baja lisonja", y que la nobleza de su Casa bastaba para establecer su grandeza ${ }^{9}$. Leti era un escritor atento a confrontar las fuentes documentales, pero de hecho, partidarios y detractores estaban entrando ya en una era más crítica, que se

7 La Mothe Le Vayer, op. cit. (nota 4, 1638). Dedicatoria al cardenal Richelieu: "vous verriez volontiers réfuter les calomnies d'une histoire, le plus contraire à la gloire de nostre nation qui puisse estre leu. Et je me suis persuadé que Vostre Eminence ne trouveroit pas hors de propos, ny peut-estre inutile, que j'aye fait voir aux Estrangers ennemis de nostre nom, comme la licence qu'ils se donnent de nous diffamer dans leurs histoires, n'est pas pour demeurer sans repartie".

8 Ibidem, p. 46: "d'une merveilleuse impertinence [...] de debuter par une si ridicule genealogie de Charles Quint, expliquée de pere en fils depuis Adam jusqu'à luy. Car encor que personne ne puisse douter de sa premiere table, depuis nostre pere commun jusques aux enfans de Noé [...] Mais de passer du texte sacré aux fables de Troye, et de coudre les veritez de la Genese avec les resveries du Berose supposé par Annius de Viterbe, et celles de l'abbé de Tritheme, qui sont les autheurs primitifs d'une si belle genealogie, je ne sçay s'il n'y a point quelque impiété".

9 Ibidem: "ceux qui se donnent aujourd'hui tant de peine pour aller chercher leur origine dans l'antiquité la plus reculée et que ses ennemis combattent", "se mirent en tête de repaitre ce grand Empereur d'une fumée de cette nature": "qu'il nétoit pas assez foible pour donner dans une si basse flaterie". LETI, G. (1630-1701): La vie de Philippe II Roi d'Espagne, Amsterdam, Pierre Mortier, 1734. Originario de Milán, estudió en un colegio de jesuitas y dejó Italia en 1657 para consagrarse a la carrera eclesiástica. En Lausana abjuró de la fe católica y se instaló en Ginebra. Llegado a la cátedra, publicó unas treinta obras hasta 1679, que se tradujeron y circularon por toda Europa confiriéndole renombre. Llegó a ser historiógrafo de Carlos II de Inglaterra (país donde sacará partido de su vena anti-romana) y en 1685 lo será de la ciudad de Amsterdam, donde murió en 1701 . 
contentaba con loar el valor de los ascendientes efectivos ${ }^{10}$. Exceptuando a Adán y a Noé con su descendencia, historiógrafos tales como François Eudes de Mézeray ${ }^{11}$ y Audigier, y genealogistas franceses como Charles Bernard, iniciaban su historia de Francia con los celtas, y la genealogía de los Borbones a partir de Clodoveo o de San Luis $^{12}$. La Historia constituía el saber real por excelencia ${ }^{13}$, pero la fábula sobrevivía tras la ambición historicista. Si los medios utilizados no recurrían ya a la escritura mitográfica, el objetivo a alcanzar seguía siendo el mismo: legitimar la preponderencia, demonstrando que la Galia céltica, o Imperio de las Galias incluyendo a "España" y a "Gran Bretaña", no esperaba sino la grandeza mesiánica de Luis XIV para ser restaurada.

\subsection{Callar la ascendencia española sin ocultarla: tortuoso ejercicio}

La acerada pluma de La Mothe Le Vayer se mostraba tanto más incisiva cuanto que se adelantaba a la descendencia común en la persona de "Luis Deodato" en setiembre de 1638. En efecto, en el privilegio de la obra impresa bajo el título Discours de l'histoire, figuraba la fecha de 16 de marzo de 1638, un mes antes del anuncio público del embarazo de la reina Ana de Austria. En un contexto de antipatía, el autor demostraba los límites previsibles de la herencia española en términos de genealogía política, y en consecuencia la imposibilidad de reinvidicar la mínima parcela de un discurso rival. Pero aquel niño, nacido del milagro consecutivo a la ferviente invocación a la Virgen, no dejaba de ser medio español, lo que explica una antipatía cada vez más matizada por parte de La Mothe Le Vayer. En efecto, dos años depués, en 1640, publicaba una Instruction à Monseigneur le Dauphin particularmente respetuosa del "honor de Francia", deseoso de ser el preceptor del Delfín para instruirle siguiendo el solo "mérito de sus ascendientes [los reyes de Francia] y de los servicios que rindieron a la Iglesia" 14 . De entrada, la galería de los parientes se anunciaba francesa. Sin embargo, Carlos V y Felipe II no estaban totalmente ausentes de ella, apare-

10 Solfaroli Camillocci, D.: “L'activité éditoriale de Gregorio Leti à Genève, entre libertinisme et tradition polémique (1661-1679)", en McKenna, A., Moreau, P. F. (dir.): Libertinage et philosophie au XVIIe siècle, Presses de l'Université de Saint-Étienne, 1996, pp. 47-69.

11 François Eudes, sieur de Mézeray (1610-1683), estudió en Caen antes de hacerse comisario de guerras en París. Desde 1637 atraerá la atención de Richelieu, que le facilitará los recursos necesarios para proseguir sus estudios de historia. En 1643 publicaba el primer volumen de su Histoire de France y en 1649 entró a la Academia francesa. A pesar de sus actividades durante la "Fronda" contra Mazarino, obtuvo el oficio de historiográfo del rey, que perdió tras la publicación en 1673-1674 de su Abrégé chronologique, donde critica la administración de Colbert.

12 Eudes de Mézeray, F.: Histoire de France, París, Denys Thierry, Jean Guignard y Claude Barbin, 1685 (primera edición de 1643 a1651, que el ayuda de Cámara, La Porte leía al joven Luis XIV); AUDIGIER: L'origine des François et de leur Empire, Paris, Claude Barbin, 1676; BERnARD, Ch.: Généalogie de la maison Royale de Bourbon avec les portraicts et les éloges des princes qui en sont sorties et les remarques historiques de leurs illustres actions, depuis le Roy S. Louis jusques à Louis le Juste XIII du nom, Roy de France et de Navarre, París, Nicolas de Sercy, 1644.

13 Cornette, J.: "Le savoir des Enfants du roi sous la monarchie absolue", en Halévi, R. (dir.), Le Savoir du Prince, París, Fayard, 2002, p. 131 y ss. Grell, CH., Les Historiographes en Europe de la fin du Moyen Âge à la Révolution française, París, PUPS, 2006.

14 La Mothe Le Vayer, op. cit. (nota 4, 1640), p. 27: “merite de ses ancestres [les Rois de France], et par les signalez services qu'ils ont rendus à l'Église". 
ciendo de vez en cuando, salpicados en diversas anécdotas mezcladas con sentencias edificantes. La intención había cambiado, y los Austrias mayores podían figurar en la instrucción del Delfín, aunque sin evocar claramente la filiación.

Así, Georges de Scudéry publicó en 1647 unos discursos ilustrados para la educación política de Luis XIV, basándose en la eficacia del exemplum como género ${ }^{15}$. Incensando a Carlos V, con el pedantismo que le caracteriza, criticaba sin embargo a su hijo Felipe II, quien, según la expresión consagrada, no podía superar al padre. En este libro dedicado a la educación política a partir de exempla, el modelo bastaba, sin que fuera necesario precisar ninguna filiación con los parientes españoles. Éstos fueron pocas veces nombrados en el parentesco de Luis XIV, y su presencia subraya una paradójica posición en la política hegemónica del rey de Francia. Los lazos de sangre podían ser evocados, en relación sobre todo con la nueva reina de Francia, y para preparar la herencia venidera, pero nunca respecto a Luis XIV mismo. Desde su matrimonio con María Teresa de Austria, la ósmosis de las dos Casas había sido elaborada por Jacques Carel, que designaba al Delfín, nacido en 1661, como Principem Hispani, mientras que Georges D'Aubusson, a quien Carel acompañó en 1661 durante su embajada en España, vislumbraba ya una posible sucesión francesa, defendiendo los derechos de María Teresa sobre Brabante y más generalmente a "las coronas de España" ${ }^{16}$. Solo Varillas, en la epístola dedicatoria del Éducation de Charles Quint de $1685^{17}$, recordaba a Luis XIV que Carlos V era su tatarabuelo. Es verdad que el contexto era diferente, pues la Paz de Nimega y el traslado de la corte a Versalles inauguraron una nueva era en la política hispánica de Francia. El discurso hegemónico galo se benefiaciaba de este acercamiento entre las dos Casas, pero la galería de los ascendientes no dejaba de seguir siendo ambigua. La ambigüedad concernía tanto a Carlos V como a Felipe II, si bien el emperador fue tratado con indulgencia por los cronistas, mientras que la obra de su hijo se vio expuesta a una leyenda negra durable.

Tales escritos no soslayaban forzosamente a las regias figuras de España, pero no evocaban el parentesco, a menudo acallado en beneficio de la invectiva, como subrayó Gregorio Leti en su obra. Leti hizo el balance de la presencia de los Austrias en la historiografía francesa, comenzando por "rechazar todo lo que la pasión hizo decir a los Franceses, los cuales para sostener los intereses de Francisco I, su Rey, trastocaron sus vicios en virtudes y, al contrario, hicieron de las más excelsas cuali-

15 Scudéry, G. de (1601-1667): Discours politiques des Rois dédiez à Monseigneur le cardinal de Mazarin, París, chez Augustin Courbin, 1647. Hacia la edad de 30 años abandonó la carrera militar para dedicarse a las letras, buscando el favor de los grandes y obteniendo el de Richelieu, que le procuró su protección. Más reservado en lo que a Mazarino respecta, se unió a la "Fronda" del Gran Condé. En 1650 accedió a la Academia.

16 Jacques Carel, sieur de Sainte-Garde, (1620-1684), limosnero y consejero del rey, publicó In Delphinum Franciae et Principem Hispaniae eodem fere tempore natos et quod ortus felicissimi animos Regum reconciliabunt, s. 1., s.d. (pero de 1662 probablemente). Acompañó a Madrid a Georges d'Aubusson, arzobispo de Ambrun (1631-1668), embajador en España entre 1661 y 1664, y autor de La defense du droit de Marie-Thérèse d'Autriche Reine de France à la succession des couronnes d'Espagne, París, Sebastien Marbre-Cramoisy, 1674. Ver Schaub, op. cit., (nota 5). Sobre la historia del acercamiento entre Francia y España, ver Valladares, R.: "Felipe II y Luis XIV”, Torre de los Lujanes, n³3 (1997), pp. 143-155.

17 Antoine Varillas (1620-1696) fue el historiógrafo de Gaston de Orléans y bibliotecario de la Biblioteca Real entre 1655 y 1662. Después ingresó en la comunidad de San Cosme, para dedicarse enteramente a la historia y publicar un número importante de obras históricas que obtuvieron una acogida moderada. 
dades de Carlos V sus faltas"18. Del mismo modo, rechazó las falsedades españolas que concernían a los franceses, de modo que su Historia retuvo casi tan sólo lo bello, evitando excesos y negando "servirse del arte de los panegíricos y de los echadores de elogios"19. Si la hispanofobia francesa fue alimentada por la política extranjera de Felipe II, no por ello el monarca hispánico cesó de ser una figura ambivalente, que irá bonificándose sensiblemente después de Richelieu merced a juicios menos estigmatizados por la pasión ${ }^{20}$. Su figura fue loada por su catolicismo militante cuando el propio Luis XIV adoptó una política procatólica. Fue sobre todo su arte de gobernar lo que se prestó a una modelización de su prudencia y gravedad, haciendo de él un misterio y un maestro en el arte del gabinete.

\section{El legado hispánico. ¿Parecerse a Carlos V?}

No obstante su proximidad genética con los Austrias de Madrid, Luis XIV tenía por enemigo hereditario a la España de sus ancestros. A tal título, Carlos V y Felipe II ocuparon un lugar discreto tanto en la educación del adolescente Luis Deodato como en la Grande Galerie o "Galería de los Espejos" del rey Sol. Cuando era tratado con indulgencia por la crítica, el emperador aparecía más como la figura de un exemplum, a la manera de las vidas paralelas de Plutarco, que como un pariente. A pesar de la antipatía hacia el héroe imperial, éste se impuso como uno de los mayores personajes del siglo precedente, capaz de contribuir a la edificación del imaginario de gloria del joven Delfín. En cuanto a Felipe II, se conjugó a su padre para aportar un modelo de virtudes principescas al aprendizaje político de un gran rey.

\subsection{Los Austrias de Madrid en los "Espejos" franceses: un turbio reflejo}

La Mothe Le Vayer, en su Instruction de 1640, rehabilita la figura filipina, maltratada por una historiografía puesta al servicio de la educación del Delfín Luis. El elogio era por entonces inédito y volvería bajo la pluma de Paul Hay, marqués du Chastelet, para servir a le educación del Gran Delfín, nacido en $1661^{21}$. En su Instruction à Monseigneur le Dauphin, La Mothe Le Vayer no renunció a las Austrias mayores, adornándoles de virtudes dignas de elevar al Delfín mediante su ejemplo. Retomando el topos de la virtud de Prudencia propria a Felipe II, que había determinado su sabiduría, el autor aborda el capítulo de la clemencia y la magnanimidad del rey hispánico frente a un súbdito maldiciente, convirtiéndose de este modo en tema de una lección sobre el beneficio que un príncipe saca de recibir "algún descontento sin resentimiento" y

18 Leti, G.: La vie de l'empereur Charles V, Amsterdam, Georges Gallet, 1708, Aviso al Lector: "par rejetter tout ce que la passion a fait dire aux François, qui pour soutenir les interests de François I. leur Roy, ont érigé ses défauts en vertus; et au contraire, ont fait des plus belles qualitez de Charles Quint des défauts".

19 Ibidem: "servir de l'art des Panégyriques et des faiseurs d'éloges".

20 Schaub, op. cit. (nota 5), pp. 246-253.

21 Paul Hay, marqués du Chastelet (1620-1682), noble de Bretaña, hijo de uno polemista afiliado a Richelieu, fue maître des requêtes y también escribano: Traité de l'éducation de Monseigneur le Dauphin, París, J. Hénault, 1664. Ver Valladares, op. cit. (nota 16), y Lahaye, M.: "Louis I'r d'Espagne (1661-1700): Essai sur une virtualité politique”, Revue Historique, n 647 (2008/3), pp. 605-626. 
de que "algo regio hay en escuchar malas palabras a cambio de buenas obras", pues "sobre los Soberanos no hablan mal los pueblos, cuando éstos otorgan la libertad de hacerlo"22. La sentencia, edificante y bien conocida, rememoraba las palabras del historiográfo español Luis Cabrera de Córdoba en el capítulo 17 de su décimo libro consagrado a Filipe Segundo Rey de España, editado en Madrid en 1619. El incidente sin duda aconteció en Santa María del Campo, durante una negociación del impuesto: un letrado, que al parecer se había quejado del rey publicamente, fue encarcelado y por fin puesto en libertad por mandato del rey. Esta misma anécdota, como tantas otras citadas por Cabrera de Córdoba, fue reutilizada por Baltasar Porreño en sus Dichos y hechos del Señor Rey Don Felipe Segundo, publicados por primera vez en 1628. La sentencia es recuperada literalmente en el capítulo quinto, dedicado a la clemencia y religiosidad de Felipe II: "Pues como dirá el pregón que dixo de mí, suéltenle, que no hay Príncipe de quien menos se quexen los suyos que del que les da más licencia para quexarse" ${ }^{23}$. Como indica en notas marginales, La Mothe Le Vayer recurrió también a los escritos de Cabrera de Córdoba, fuente principal de las relaciones más hagiográficas de la vida de Felipe II, pero quizás el autor bebió directamente en Porreño, como el paralelismo entre los extractos que citamos en nota infra permite suponer. El género apologético y anecdótico de Porreño tenía un precedente en la obra del madrileño nativo de Holanda, Lorenzo van der Hammen y León, que publicó en Madrid en 1625 Don Filipe el Prudente, Segundo deste nombre, Rey de las Españas y Nuevo Mundo. La obra de Porreño, acabada un año después, quedó ampliamente influenciada por la de Lorenzo van der Hammen. Estos dos autores fueron los dos principales panegiristas de Felipe II, recurriendo a

22 La Mothe Le Vayer, op. cit. (nota 5, 1640), p. 55: “quelque déplaisir sans ressentiment”, “qu'il y a quelque chose de royal a entendre de mauvaises paroles pour de bonnes œuvres" y "qu'il n'y a point de Souverains dont les peuples parlent moins desavantageusement, que de ceus qui leur donnent toute liberté de le faire".

23 Porreño, B.: Dichos y hechos del Señor Rey Don Felipe Segundo El Prudente, potentíssimo y glorioso monarca de las españas y de las Indias, [Sevilla, Pedro Gomez de Pastrana, 1639], introducción de Antonio Álvarez-Ossorio Alvariño, Madrid, Sociedad Estatal para la Conmemoración de los Centenarios de Felipe II y Carlos V, 2001, p. 40. A título comparativo, citamos los tres extractos: La Mothe Le Vayer, p. 55 de l'Instruction...: “Un homme qui n'avoit jamais eu l'honneur de parler à sa Majesté, et qui n'en avoit aussi receu aucun deplaisir, ne laissa pas d'estre emprisonné pour avoir esté si temeraire que d'en mesdire publiquement. Ce genereus Prince le fit mettre en liberté aussi-tost qu'il fut informé de la qualité de son crime, sans lui faire souffrir autre mal, que le jugement qu'il fit de sa personne, disant, qu'un autre qu'un fou parfait n'auroit jamais sans estre offensé parlé de la sorte de celui qu'il ne connoissoit point. A quoi il adjousta ceste belle sentence, qu'il n'y a point de Souverains dont les peuples parlent moins desavantageusement, que de ceus qui leur donnent toute liberté de le faire." Cabrera de Córdoba, p. 788 en Filipe Segundo...de 1619: "Insistando el Presidente an que fuese castigado en la Corte por el exemplo; le replicó: Pues como dira el pregon, que dixo de mi Sueltenle Que no ai Principe de quien menos se quexen los suyos, que del que les da mas licencia para ello. O grave sentencia, porque la ultima señal de servidumbre es quitar el quexarse”. Porreño, p. 40 (edición 2001) du Dichos y hechos...: "Lo que resultó de todo esto fue mandar su Magestad que se le diesse libertad porque devía de ser loco el que dezía mal de quien ni conocía ni avía hablado en su vida, ni le avía hecho daño; y haziendo instancia el Presidente en que fuesse castigado en la Corte por el exemplo, le replicó su Magestad: "Pues como dirá el pregón que dixo de mí, suéltenle, que no ay Príncipe de quien menos se quexen los suyos que del que les da más licencia para quexarse”. ¡Oh grave sentencia digna de tan gran Monarca, que considerava altamente que la última señal de servidumbre es quitarle a un atribulado el quexarse!". 
Cabrera de Córdoba o a Fernando de Herrera ${ }^{24}$. Así La Mothe Le Vayer había bebido en las fuentes más hagiográficas del rey más temido y odiado por los franceses en tiempo de las Guerras de Religión.

En cuanto a Carlos V, fue elevado al rango de las grandes figuras heroicas merced al discurso de grandeza de los primeros Austrias, que habían inspirado temor y admiración, combinando leyenda negra y leyenda rosa. Georges de Scudéry lo ilustró en sus Discours politiques, proponiendo al joven rey en 1647 cierto número de retratos regios por mediación de Mazarino. Maestro en el arte del elogio, Georges de Scudéry alzará a Carlos V al rango de las grandes figuras, dignas de ser imitadas, prestando la palabra al propio emperador a través de un diálogo con sus hermanas durante el último viaje, imaginado en la nave que les transporta a España. El emperador hace su propio elogio y el heroísmo que le caracteriza aparece en todo comparable a la heroica grandeza de los emperadores romanos. Desde la elección imperial en 1519 hasta la victoria de Pavía, "Carlos fue preferido a Francisco I" ${ }^{25}$, y el saco de Roma y la política heroica del emperador contra los Turcos le hicieron "escudo de toda la Cristiandad", vencedor del "Águila romana en lugares donde nunca aquélla había aparecido desde la derrota de Aníbal y la victoria de Escipión" 26 . Su gesta triunfal le permite mostrarse como el único héroe comparable a los antiguos césares y a Carlomagno: "Dios guía a César y a su Fortuna" para cumplir su voluntad, pues como Carlos V recuerda a sus hermanas "mi causa es la de Dios", justificando así las guerras emprendidas en nombre de la Monarquía Universal y de su elección providencial para extender su Imperio más allá de las tierras conocidas, "más allá de las columnas de Hércules"27.

Como héroe del Renacimiento, grande por su arrojo y victorioso, Carlos V es también un ser virtuoso, inspirado por la Prudencia que le aleja de los reversos de Fortuna que podría infligirle su mediocre estado de salud, prefiriendo "para vivir eternamente en la memoria de los hombres", dejar "el mando de una gran nave [...] y abandonarlo en manos de un joven Timonel, que no teniendo tanta experiencia como Vos, no tendrá tampoco tanta habilidad"28. El elogio es claro como clara es también la crítica hacia Felipe II, pues, en 1647, la hispanofobia francesa sigue bien viva. Un buen francés se aferra a su hispanofobia y no respeta en Carlos V más que lo que encierra de figura edificante, no de gobernante enemigo del reino de Francia, que además era más gantés que español, como subraya Scudéry: "Sin embargo, si en el estado en que están las cosas, un francés puede permitirse loar a un

\footnotetext{
24 Ver el estudio introductorio de Antonio Álvarez-Ossorio Alvariño en la edición de 2001, a cargo de la Sociedad Estatal para la Conmemoración de los Centenarios de Felipe II y Carlos V. La Mothe Le Vayer conocía la obra en castellano del historiogáfo español, y quizas también la de Porreño, que fue traducida al francés y publicada en 1671 en Colonia, con el título Recueil des actions et paroles memorables de Philippe Second.

25 Scudery, op. cit. (nota 15), p. 9: "Charles a esté preferé à François".

26 Ibidem, p. 14: "l'Aigle romaine en des lieux où elle n'avoit jamais paru, depuis la deffaite d'Hannibal, et la victoire de Scipion".

27 Ibidem, pp. 16 y 18.

28 Ibidem, pp. 19-20: "pour vivre eternellement en la memoire des hommes", " le timon d'un grand vaisseau [...] et l'abandonner aux soings d'un jeune Pilote, qui n'ayant pas tant d'experience que vous, n'aura pas non plus tant d'adresse".
} 
español (suponiendo que un príncipe nacido en Flandes pueda llevar tal nombre), me permitiría decir que la acción del emperador Carlos $\mathrm{V}$ fue grande y hermosa, $\mathrm{y}$ absolutamente heroica" ${ }^{29}$. Después del nacimiento del Delfín en 1638, deseosos de servir a su educación, los denigradores de España recorrieron a este tipo de sutiles artificios para ahorrar pullas a los parientes españoles del rey, sin renunciar a su hispanofobia.

Después de 1700 y del testamento de Carlos II, los Austrias mayores, hasta ahora ambivalentes, recobraron casi el lustre de su glorioso pasado bajo la pluma de Amelot de la Houssaye, que dedica todo un capítulo al Austria en sus Mémoires historiques. A propósito de los dos grandes Austrias escribe: "Los Españoles le han comparado [a Carlos] con David a causa de su reinado militar, y a Felipe Segundo con Salomón, en razón de su reinado pacífico; y especialmente porque ha construido el magnífico Templo de El Escorial" ${ }^{30}$. Felipe V, nuevo rey de España, reconciliará los dos parentescos, haciéndose representar con los atributos propios de las dos dinastías a fin de perpetuar el legado común y de "regenerar" la sangre de los Austrias con la de los Borbones ${ }^{31}$. Pero no es ésta aquí materia nuestra, y antes de ese futurísimo momento de encuentro, los Austrias mayores representarán sobre todo figuras enemigas y diana de los historiógrafos y cronistas franceses.

\subsection{Carlos V: un modelo crítico}

Antoine Varillas, cronista de carrera irregular, fue sin duda el autor más prolijo sobre la Casa de Austria y las coronas ibéricas. Pretextando un punto de vista histórico, disimula una crítica acerba contra los Austrias bajo sentencias ambiguas. La edición princeps de su Politique de la maison d'Autriche, publicada en 1657, se abre con un elogio del gobierno de Felipe II, de sus consejos y su obra de centralización administrativa mediante la fijación de la Corte, en sentido amplio, entre

29 Ibidem, p. 35: “Cependant, s'il est permis en l'estast que sont les choses, à un François, de loüer un Espagnol (si toutesfois un Prince qui estoit né en Flandres peut porter ce Nom) j'oseray dire que l'action de l'Empereur Charles Quint fut grande et belle, et absolument héroïque."

30 Amelot De La Houssaye, N. (1634-1706): Mémoires historiques, politiques, critiques et littéraires, Amsterdam, chez Michel Charles le Cene, 1724, p. 192. Fue secretario de embajada en Venecia en 1669, así como traductor de obras italianas y castellanas. Redactó estas memorias tras conocerse el testamento de Carlos II: "Les Espagnols l'ont comparé à David à cause de son règne tout militaire, et Filippe Second à Salomon, à cause de son règne pacifique; et particulièrement pour avoir bâti le magnifique Temple de l'Escurial'.

31 "En la imagen dinámica de Felipe V, tanto iconográfica como literaria, se funden los Austrias mayores y los Borbones, Carlos V y Luis XIV victoriosos, Marte y Hércules" escribe Torrione, M.: "La imagen de Felipe V en el grabado francés de la guerra de Sucesión", in Álvarez-Ossorio Alvariño, A. y otros (eds.): La Pérdida de Europa. La guerra de Sucesión por la Monarquía de España, Madrid, Fundación Carlos de Amberes, 2007, p. 27 [21-48], y también SABATIER, G.: "VACVA MElior NVNC REgNet In AVla. La guerre des médailles entre Philippe V de Bourbon et Charles III de Habsbourg pendant la guerre de Succession d'Espagne (1700-1711)", p. 65-98, cita el ejemplo de una medalla acuñada con motivo de la Entrada madrileña del 14 de abril de 1701, mostrando a Felipe V entre dos columnas, bajo un sol resplandeciente, que reivindica el doble patronazgo de Carlos V y de Luis XIV. Véase la gaceta de Madrid del 8 de marzo 1701 ( $\left.{ }^{\circ} 10\right)$, donde aparece un soneto dedicado a Felipe V: "Con Austriaco desvelo / victima de amor se ofrece / el que ya à Carlos parece", en Torrione, M. (ed.): Crónica festiva de dos reinados en la Gaceta de Madrid (1700-1759), París, Ophrys, 1998, p. 32. 
Madrid y El Escorial. Reconociendo la grandeza de la política española, Varillas adopta en sus preliminares un tono neutro -según él ingrediente necesario a la verdad histórica- pero bajo el elogio subyace una línea de fractura con los enemigos de siempre: "Rindo a la verdad, en la persona de nuestros enemigos, el testimonio que exige desde el comienzo de mi obra", y prosiguiendo en el mismo tono añade: "trazo las raras cualidades de algunos príncipes de la Casa de Austria, según la idea que de ella tengo, y no ahorraré alabanza a sus Ministros por las laudables acciones realizadas, aunque hayan redundado en perjuicio de mi país" 32 . Luego oscila entre el reconocimiento limitado de sus grandes hazañas y la denigración de las mismas, denunciando las "intrigas de Carlos V", y el rebajamiento del Imperio. Tanto Antoine Varillas como La Mothe Le Vayer se mostraron reticentes en peremnizar este reconocimiento de la grandeza austríaca, atenuándola al mismo tiempo con una crítica circunstancial.

Se reprochaba con frecuencia a Carlos V su fracaso frente a los príncipes protestantes del Imperio y contra los infieles, por flaqueza e inacción, de modo que el héroe -siéndolo él- resulta una figura adecuada para esclarecer otra igualmente heroica, la de su adversario Francisco I. Antoine Varillas imputaba a "la insistencia de sus amigos" la existencia de un libro decimotercio insertado en su Histoire de François premier, publicado en 1685 y basado en la comparación entre el rey de Francia y el emperador del Sacro Imperio. Detrás de este "Paralelo de dos héroes del pasado Siglo", Varillas procuró hacer ante todo el elogio de Luis XIV, que habiendo vencido a los genoveses, superó a ambas figuras y borró la injuria hecha al rey de Francia por la traición de Génova, considerada principal causa del infortunio galo frente al emperador ${ }^{33}$. La comparación sirve para desmitificar a Carlos $\mathrm{V}$ y consiguientemente al imperio habsbúrgico. Para restablecer el "honor de Francisco I", nada mejor que menoscabar el Imperio y no seguir temiéndolo, como hicieran quienes lo creyeron inexpugnable. Deshonroso sería, en efecto, temer a un emperador inferior a su enemigo francés cuya conducta, aunque irregular en ocasiones, "dista de los vicios de Carlos V, al que alzan, empero, por encima de todos los emperadores desde Carlomagno" "34. Su común destino fue un efecto de la providencia, sacando "su principal brillo el uno del otro", de donde la extinción del astro habsburgo tras la muerte de Francisco I en 1547: "El otro se quedó sin virtud y acumuló los errores". El juicio no soporta ya aquí ninguna ambivalencia, llegando hasta a despreciar la herencia de Carlos V y denunciar la sangre de España, corrompida por la locura de Juana de Castilla, su madre, por un Fernando el Católico perjuro, y demás ascendientes viciosos. La dudosa "probidad de los antepasados" de Carlos V confiere tanto más brillo a la grandeza del "linaje de los Capetos".

32 Varillas, A.: La politique de la maison d'Autriche, París, Claude Barbin, 1688, pp. 29 y 53: "Je represente les rares qualitez de quelques Princes de la Maison d'Autriche, suivant l'idée que je m'en suis formée, et je ne refuse point d'Eloges a leurs Ministres pour les belles actions qu'ils ont faites, quoi qu'elles aient reussi au desavantage de mon païs."

33 Varillas, A.: Histoire de François premier, París, Claude Barbin, 1685, libro 13, p. 103.

34 Ibidem, libro 13, I: " $n$ 'approche pas des vices de Charles Quint, qu'ils élèvent pourtant au-dessus de tous les Empereurs depuis Charlemagne". 
Sólo la educación del emperador es auténticamente loable, aunque no hizo de él un príncipe tan físicamente fuerte como el rey de Francia y tan amante de las bellas letras. Además, si su educación fue buena se debió al celo de los franceses, que elegieron por ayo a De Chièvres, lo que Antoine Varillas explica en 1685, en su Éducation de Charles Quint. Insiste, con complacencia, sobre el hecho de que "es la educación, Señor, del héroe de la Casa de Austria, el Emperador Carlos V, vuestro tatarabuelo materno" ${ }^{35}$, la que los españoles, a su pesar, deben a Luis XII:

Los Españoles la alaban [la educación] en proporción al fruto que de ella sacan. Pero no osarían negar que la deben al Rey Luis Duodécimo que dio a Carlos por ayo la persona de Chièvres, el hombre de Europa más capacitado para educarle bien. Sin embargo, parece que se avergüenzan de haber recibido de Francia un beneficio tan raro, que antes prefieren callarlo que reconocerlo ${ }^{36}$.

Si Chièvres infundió su talento en el emperador -que es el de "tratar con las naciones con las que tendrá relación proporcionadamente a su genio"-, esta educación desvela sus defectos y eleva a Luis XIV: "Carlos V necesitó aprender el arte de reinar con Chièvres, y Vuestra Majestad se ha formado a sí misma. Carlos no encontró ningún ascendiente que pudiera servirle de modelo para guiar su vida, y fue por pura necesidad por lo que los buscó fuera de su Casa". Y Varillas concluye con ostentosa parcialidad sobre esta ausencia de modelo habsbúrgico y el rechazo del antepasado: "Vuestra posteridad, Señor, será más feliz de lo que Carlos lo fue nunca, porque no sólo no tendrá que buscar un modelo, sino que encontrará en la propia persona de Vuestra Majestad, las singulares virtudes que aquél se propuso imitar a través de los héroes de todos los siglos que le precedieron" ${ }^{37}$.

Por aquellos años de 1680 que consagraron la hegemonía francesa, las obras de Varillas evocaron la filiación con los Austrias sin dejar de criticarlos, aunque sin la ambigüedad que encerraban los discursos destinados a la educación del Delfín cuarenta años antes. El tono del historiógrafo hacía eco al arrogante programa iconográfico de la Grande Galerie del palacio Versalles, acabada en la misma época, donde las pinturas de Le Brun reflejan los triunfos del Rey Sol: el león tantas veces sometido a Francia en armas, a través de La preeminencia de Francia reconocida por España en 1652, La Paz concluida a Aix-la-Chapelle en 1668, o bien ese águila imperial fulminada por un rayo del rey sentado sobre el ave olímpica: las columnas de Hércules se han venido abajo y la divisa del emperador, Plus Ultra, se ha des-

35 Varillas, A.: La Pratique de l'éducation de Charles Quint, París, Claude Barbin, 1684, epístola dedicatoria: “C'est l'éducation, SIRE, du Heros de la Maison d'Autriche l'Empereur Charles Quint vôtre Tri-ayeul maternel",

36 Ibidem: "Les Espagnols la loüent [l'éducation] à proportion du fruit qu'ils en tirèrent: Mais ils n'oseroient nier qu'ils n'en soient redevables au Roy Louis Douze, qui donna à Charles pour Gouverneur en la personne de Chievres, l'homme de l'Europe le plus capable de le bien élever. Il semble pourtant qu'ils ayent honte d'avoir receu de la France un si rare Bienfait, puisqu'ils aiment mieux le passer sous silence, que de l'avoüer".

37 Ibidem: "Vôtre Postérité, SIRE, sera plus heureuse que Charles ne le fut, puisque non seulement elle n'aura pas besoin de chercher ailleurs un Modele; mais encore elle trouvera dans la seule Personne de Vôtre majesté, les vertus singulieres qu'il se proposa d'imiter dans les Heros de tous les Siecles qui l'avoient précedé". 
hecho $^{38}$. Esta pintura de Le Brun para la Galería, titulada Holanda acepta la Paz y se desliga del Imperio y de España en 1678, glorifica a Luis XIV y ensalza la potencia francesa, expresando la voluntad de superar el embarazoso modelo español, simplemente porque antaño había sido hegemónico y sus ilustres representantes eran antepasados del nuevo Carolus redivivus. Si Carlos V, Felipe II, Fernando de Aragón incluso, fueron figuras ejemplares y dignas de una lección reservada al príncipe, nunca llegaron a ser figuras de identificación por excelencia.

\section{3. ¿Qué modelo heroico para Luis XIV?}

Los frecuentes elogios y panegíricos hicieron a menudo de Luis XIV el alpha de una raza regenerada y de una nueva era política, anunciadora de la preponderancia francesa. Fue, pues, en la historia de Francia donde el rey forjó su gloria y su sueño de grandeza ${ }^{39}$. En aquella historia que le gustaba oir cuando por la noche La Porte ${ }^{40}$, su gentilhombre de cámara, le leía la de Mézeray, Enrique IV fue sin duda su modelo de héroe. Hardouin de Péréfixe, preceptor, redactó una historia de Francia prestando una atención particular al primer rey de la dinastía de Borbón, cuya biografía constituyó el punto de arranque de su obra ${ }^{41}$. Péréfixe lo explica conforme al deseo que sintió de satisfacer la natural inclinación de su alumno:

Hubiera preferido acabar esta Obra y sacarla a la luz completa: mas el particular afecto que el Rey me ha demostrado sentir siempre hacia su pariente Enrique el Grande, y la declaración que tan a menudo ha hecho de que deseaba tomarle por modelo, me han urgido a poner en limpio esta parte de mi trabajo, y a separarla de las restantes ${ }^{42}$.

Enrique IV había sido la figura ancestral del linaje borbónico y había iniciado su reinado en un tiempo de paz, restaurando así cierta idea de la Edad de Oro. Héroe pacificador, integró su propio mito gracias a la viva memoria del amor de sus subditos:

38 SABATIER, op. cit. (nota 2, 1999), p. 382.

39 Sobre la historiografía francesa y la realeza, remito al artículo de Michel Tyvaert, cuyo análisis más exhaustivo atenúa la importancia del modelo heredado de Enrique IV, "L’image du roi : légitimité et moralités royales dans les histoires de France au XVIIe siècle ", Revue d'histoire moderne et contemporaine, tomo XXI (1974), pp. 521-547.

40 Lacour Gayet, G.: L'éducation politique de Louis XIV, París, Hachette, Bibliothèque d'Histoire, 1923, p. 79.

41 Hardouin de Beaumont de Péréfixe (1605-1671) fue el preceptor de Luis XIV en 1642, obispo de Rodez en 1648, y miembro de la Academia en 1654.

42 Hardouin de PéréfiXe: Histoire du roi Henri Le Grand, París, Bailly, 1786, epístola a Mazarin: “J’aurois bien souhaité de mettre au jour cet Ouvrage tout entier en même tems: mais l'affection particuliere que le Roi m'a toujours temoignée pour la vie de son Ayeul Henri Le Grand, et la declaration qu'il a faite si souvent, qu'il vouloit se le proposer comme son modele, m'ont hâté de mettre au net cette partie de mon travail, et de la séparer des autres". 
Señor, el respeto y el amor que todos los buenos Franceses han conservado siempre por la feliz memoria del rey Enrique el Grande, vuestro abuelo, le hacen estar tan presente en su recuerdo como si aún reinara; y la fama conserva el brillo de sus bellas acciones en el corazón y en la boca de los hombres, tan vivo y entero como lo estaba en tiempo de sus triunfos ${ }^{43}$.

No puede haber modelo mas ventajoso que el de este rey neoestoico que invita a su heredero a superarle: "Pero se puede decir con esto, cuando se considera a Vuestra Majestad, que vive de nuevo en vuestra Persona, y que se deja ver hoy con una apariencia aún más augusta..." 44 .

De manera similar, François de Bretaigne evocaba, en 1651, la restauración de la Edad de Oro enriqueña, resucitando al héroe paterno:

La primera dió a los Franceses cansados de sus guerras civiles, un Hijo de Enrique el Grande, para ser el heredero de sus virtudes y de su cetro; la última hace todavía vivir a este Héroe y demuestra que el Cielo le riende Justicia, conservando una Corona para su posteridad, que no es menos herencia que conquista suya ${ }^{45}$.

La ecuación ideal entre ambos monarcas conforta a Péréfixe en su elección, evocando para ello el deseo de Luis XIV de tenerle por "modelo" (recurrente en el texto) y el marcado placer del rey en escuchar su historia: "la loable impaciencia, que Vuestra Majestad manifestaba cuando le hacía yo leer nuestra Historia, por llegar al glorioso reinado de este príncipe, [...] es prueba muy cierta de que desea tomarlo por modelo". Este exemplum resulta probante, a través de la idea de herencia que se nombra y se alaba sin embarazo porque está asociado al pasado y al porvenir del reino. En el esquema clásico del modelo basado en la filiación, los héroes se legan ante todo sus virtudes que son las cualidades del alma, la fuerza, el valor, como también el juicio. A Felipe II se le había alabado gracias a las virtudes de su padre. Luis XIV debía serlo a través de las de un Borbón, no de las de un Habsburgo: "Recuerde, por favor, que me ha honrado diciéndome muchas veces que aspiraba con ansia a similar perfección, y que no tenía mayor ambición que ésta" 46 . Péréfixe insiste mucho sobre este "placer", esta "ambición” de Luis XIV, quizás porque el

43 Ibidem: "Sire, Le respect et l'amour que tous les bons François ont toujours conservés pour l'heureuse mémoire du roi Henri Le Grand votre aïeul, le rendent aussi present à leur souvenir comme s'il régnoit encore; et la renommée entretient l'éclat de ses belles actions, dans le cœur et dans la bouche des hommes, aussi vif et aussi entier qu'il l'étoit du tems de ses triomphes".

44 Ibidem: "Mais on peut dire avec cela, lorsque l'on considere Votre Majesté, qu'il a repris une nouvelle vie en votre personne, et qu'il se fait voir aujourd'hui sous un visage encore plus auguste..."

45 Bretaigne, F. de: Le Roy mineur ou panégyrique sur la personne et l'éducation de Louis XIV Dieudonne Roy de France et de Navarre dédié à Monseigneur le Maréchal de Villeroy, París, Jean Henault, 1651, p. 14: "La première donnoit à nos François fatiguez de leurs mouvemens civils, un Fils d'Henri le Grand, pour estre l'heritier de ses vertus, et de son sceptre, la derniere fait encore vivre ce Heros, et monstre que le Ciel luy fait Iustice, en conservant à sa posterité une Couronne, qu'on pouvoit moins dire son heritage, que sa conqueste".

46 Hardouin de PéréfiXe, op. cit. (nota 42), pp. 1-4: “Souvenez-vous, s’il vous plaît, que vous m'avez fait l'honneur de me dire plus d'une fois, que vous aspiriez fortement à une semblable perfection, et que vous n'aviez point de plus grande ambition que celle-là'. 
modelo que se hereda es también, por definición, una ambición esbozada a través del discurso imaginario de gloria.

Luis XIV igual a Enrique el Grande, pero en realidad mayor que Augusto, Carlomagno y Enrique IV. Los modelos existen para ser superados y el modelo es francés, mientras que los Habsburgo de España, víctimas de su hegemonía pretérita, siguen siendo enemigos y antepasados impronunciables. El discurso mesiánico de Luis XIV se demostró suplantando el discurso hegemónico español pero apropiándose su tradición teórica ${ }^{47}$. Este traslado de competencias mesiánicas fue enunciado por los turiferarios de Luis XIV, empezando por Corneille en su obra teatral $L a$ Toison d'Or, estrenada en enero de 1661 celebrándose los esponsales del rey con María Teresa de Austria ${ }^{48}$. Luis XIV era ahora el Jasón que se apoderaba del dorado Vellocino de los Austrias ${ }^{49}$.

47 Édouard, S.: "Le messianisme de Louis XIV, un modèle espagnol?", en TorRione, M. y SABatier, G. (dirs.): ¿Louis XIV espagnol? Madrid et Versailles, images et modèles, Éditions de la Maison des Sciences de l'Homme \& Centre de Recherches du Château de Versailles, Col. "Aulica", 2009.

48 Galactéros De Bossier, L.: "Jason à la conquête de la Toison d'or: Les fêtes lyonnaises de 1658", Mélanges offerts à Georges Couton, Lyon, PUL, 1981; WAGNer, M. F.: "Vision métaphorique du roi dans La conquête de la toison d'or de Pierre Corneille", Renaissance and Reformation, 10, №2 (1986), pp. 217-27.

49 ZANGer, A.: Scenes from the marriage of Louis XIV. Nupcial Fictions and the Making of Absolutist Power, Stanford, CA, 1997. En opinión de Perceval, J. M.: "Épouser une princesse étrangère : les mariages espagnols ", Poutrin, I. y SchauB, M. K. (dir.): Femmes et pouvoir politique. Les princesses d'Europe XVeXVIIIe siècle, Bréal, 2007, p. 70, se trata de una actualización del tema del Toisón de Oro y no de una posible analogía con los personajes de Jasón y Medea. 